Review Article

\title{
Classification and Clinical Diagnosis of Fibromyalgia Syndrome: Recommendations of Recent Evidence-Based Interdisciplinary Guidelines
}

\author{
Mary-Ann Fitzcharles, ${ }^{1}$ Yoram Shir, ${ }^{2}$ Jacob N. Ablin, ${ }^{3}$ Dan Buskila, \\ Howard Amital, ${ }^{5}$ Peter Henningsen, ${ }^{6}$ and Winfried Häuser ${ }^{6,7}$ \\ ${ }^{1}$ Division of Rheumatology, McGill University Health Centre, Alan Edwards Pain Management Unit, \\ McGill University Health Centre, Canada H3G 1A4 \\ ${ }^{2}$ Alan Edwards Pain Management Unit, McGill University Health Centre, Canada H3G 1A4 \\ ${ }^{3}$ Department of Rheumatology, Tel Aviv Sourasky Medical Center, 64329 Tel Aviv, Israel \\ ${ }^{4}$ Department of Medicine, H. Soroka Medical Center, 84101 Beer-Sheva, Israel \\ ${ }^{5}$ Department of Medicine "B" and Centre for Autoimmune Diseases, Sheba Medical Centre, 52621 Tel Hashomer, Israel \\ ${ }^{6}$ Department Internal Medicine I, Klinikum Saarbrücken, Winterberg 1, 66119 Saarbrücken, Germany \\ ${ }^{7}$ Department of Psychosomatic Medicine and Psychotherapy, Technische Universität München, 81865 München, Germany
}

Correspondence should be addressed to Winfried Häuser; whaeuser@klinikum-saarbruecken.de

Received 9 April 2013; Accepted 1 October 2013

Academic Editor: Romy Lauche

Copyright (C) 2013 Mary-Ann Fitzcharles et al. This is an open access article distributed under the Creative Commons Attribution License, which permits unrestricted use, distribution, and reproduction in any medium, provided the original work is properly cited.

Objectives. Fibromyalgia syndrome (FMS), characterized by subjective complaints without physical or biomarker abnormality, courts controversy. Recommendations in recent guidelines addressing classification and diagnosis were examined for consistencies or differences. Methods. Systematic searches from January 2008 to February 2013 of the US-American National Guideline Clearing House, the Scottish Intercollegiate Guidelines Network, Guidelines International Network, and Medline for evidence-based guidelines for the management of FMS were conducted. Results. Three evidence-based interdisciplinary guidelines, independently developed in Canada, Germany, and Israel, recommended that FMS can be clinically diagnosed by a typical cluster of symptoms following a defined evaluation including history, physical examination, and selected laboratory tests, to exclude another somatic disease. Specialist referral is only recommended when some other physical or mental illness is reasonably suspected. The diagnosis can be based on the (modified) preliminary American College of Rheumatology (ACR) 2010 diagnostic criteria. Discussion. Guidelines from three continents showed remarkable consistency regarding the clinical concept of FMS, acknowledging that FMS is neither a distinct rheumatic nor mental disorder, but rather a cluster of symptoms, not explained by another somatic disease. While FMS remains an integral part of rheumatology, it is not an exclusive rheumatic condition and spans a broad range of medical disciplines.

\section{Introduction}

Roughly $2 \%$ of the developed world's population meet either the 1990 classification or 2010 modified diagnostic criteria of the American College of Rheumatology (ACR) for fibromyalgia syndrome (FMS) [1-5]. FMS patients report a wide array of somatic and psychological symptoms, with each contributing to a varying degree of symptom burden and functional disablement $[6,7]$. FMS continues to present a challenge for healthcare professionals of various disciplines as well as for patients. Areas of contention include the benefits or harms of the diagnostic label "FMS," the classification of the syndrome (rheumatic, neurologic, psychological disorder or a functional somatic syndrome), and the tender point examination that surfaced as a new physical finding two decades ago $[8,9]$. The aim of the current review is to compare the recommendations of recent evidence-based interdisciplinary guidelines to identify consistencies but also to examine the presence of any 
contradictory conclusions regarding the definition (labelling) and clinical diagnosis of FMS.

\section{Materials and Methods}

2.1. Search of Literature. A systematic search of the US Agency for Healthcare Research and Quality (AHRQ) American National Guideline Clearing House (NGC) (http:// www.guideline.gov/), the Scottish Intercollegiate Guidelines Network (SGN) (http://www.sign.ac.uk/guidelines/index .html), and the Guidelines International Network (G-I-N) (http://www.g-i-n.net/) was conducted from January 2008 to February 2013, using the key words "Fibromyalgia" and "Fibromyalgia Syndrome." Medline was also searched from January 2008 to February 2013 with the search terms "Guideline" (publication type) and "Fibromyalgia" (mesh). Because regular updates of guidelines are required by guideline clearing houses, the searches were limited to this period. A manual search of the guideline bibliographies and contacts to international FMS key opinion leaders was undertaken to verify that all published guidelines were identified.

2.2. Inclusion Criteria. To be included in our analysis, the guidelines had to meet the following criteria.

(1) The guideline was commissioned by a scientific organisation.

(2) The guideline group was interdisciplinary and included at least the specialties rheumatology, pain medicine, and psychiatry or psychosomatic medicine or clinical psychology.

(3) A systematic search strategy was outlined.

(4) Recognized criteria of classification evidence and recommendations were used.

(5) The formal process for establishing recommendations (Delphi exercise, panel conference) was outlined.

Guidelines that included FMS with other diagnoses, such as chronic fatigue syndrome, myalgic encephalomyelitis, or somatoform disorders, were excluded.

2.3. Analysis of the Guidelines. Inclusion criteria and the composition of the steering committees and panels, search strategies, the classification of evidence and recommendations, the procedures for establishing recommendations, and the recommendations given by the guidelines that met inclusion criteria were assessed by two independent reviewers (Mary Ann Fitzcharles, Winfried Häuser). All discrepancies were rechecked and consensus achieved by discussion. If needed a third reviewer was involved (Jacob N. Ablin).

\section{Results}

3.1. Guideline Selection. The literature search yielded 24 citations (1 in NGC, none in SIGN, 2 in GIN, and 21 in Medline). FMS opinion leaders reported two guidelines. Three of these met our inclusion criteria: the 2012 Canadian Guidelines for the diagnosis and management of fibromyalgia syndrome [10], the guidelines of the Association of the Scientific
Medical Societies in Germany (AWMF) on the definition, pathophysiology, diagnosis, and treatment of fibromyalgia syndrome [11-19], and the Israeli guidelines for the diagnosis and treatment of fibromyalgia syndrome [20]. The reasons for excluding other hits were as follows: duplications $(n=19)$, not commissioned by a scientific society $(n=2)[21,22]$.

3.2. Organisations Asked for the Development of the Guidelines. The Canadian guidelines were endorsed by the Canadian Pain Society (CPS) and the Canadian Rheumatology Association (CRA). The guidelines were developed by the Canadian Fibromyalgia Guidelines Committee (CFGC) [10].

The German guidelines were initiated and coordinated by the German Interdisciplinary Association of Pain Therapy (DIVS). The DIVS, an umbrella organisation of 18 scientific societies, is dedicated to the improvement of interdisciplinary pain therapy. The methodological development of the guidelines was supported by the Association of the Scientific Medical Societies (AWMF), the umbrella organisation of 152 scientific medical societies in Germany. Nine scientific associations (children and juvenile rheumatology, neurology, orthopedic surgery, pain medicine, pain psychology, physical therapy, and rehabilitation medicine, rheumatology, psychiatry, and psychosomatic medicine) and two national FMS selfhelp organisations participated in the guidelines development [11].

The Israeli guidelines were developed by the Israeli fibromyalgia group, on behalf of the Israeli Rheumatology Association. This group was formed within the national rheumatology association and included a group of experts with both clinical and research interest in FMS [20].

3.3. Composition of the Working Groups and Sources of Funding for the Guidelines. Details of the guideline groups are outlined in Table 1.

The development of the guidelines was funded by a private foundation (Canada), pharmaceutical companies (Canada, Israel), and the scientific societies involved (Germany, Israel). All three guideline groups comprised multidisciplinary teams representing healthcare professionals from relevant fields involved in the care of FM patients.

3.4. Methodologies. Details of the composition of the methodologies to design levels of evidence and grades of recommendations are outlined in Table 2.

The levels of evidence were assigned according to the classification system of the Oxford Centre for Evidence Based Medicine [23] by the Canadian and German guidelines $[10,11]$. Both guidelines defined criteria for up- and downgrading the level of evidence. Grading of the strengths of recommendations was done according to the standards set out by the Oxford Centre for Evidence Based Medicine [23] for the Canadian guidelines and by the program for disease management guideline for the German guideline [24]. The Canadian guidelines were reviewed by an international expert and thereafter underwent external review requested by the Canadian Pain society using the AGREE II Score Sheet guideline appraisal tool [25]. The German guidelines were 
TABLE 1: Comparison of the composition of the guideline groups and the funding of the Canadian, German, and Israeli guidelines.

\begin{tabular}{|c|c|c|c|}
\hline & Canada & Germany & Israel \\
\hline Nomination of members of the guideline group & $\begin{array}{l}\text { Nominated by Canadian } \\
\text { scientific societies }\end{array}$ & $\begin{array}{l}\text { Nominated by German } \\
\text { scientific societies or } \\
\text { self-help organisations }\end{array}$ & $\begin{array}{l}\text { Nominated by Israeli } \\
\text { scientific societies or } \\
\text { self-help organisations }\end{array}$ \\
\hline Number of members in steering committee & 11 & 12 & 11 \\
\hline \multicolumn{4}{|l|}{$\begin{array}{l}\text { Clinical expertise of members of steering } \\
\text { committee }\end{array}$} \\
\hline Rheumatology/internal medicine & 3 & 2 & 9 \\
\hline Pain therapy & 1 & 1 & 0 \\
\hline Orthopedics/rehabilitation & 1 & 2 & 0 \\
\hline Neurology & 1 & 1 & 0 \\
\hline Pediatrics & 0 & 1 & 0 \\
\hline Family medicine & 1 & 0 & 1 \\
\hline Pharmacology & 0 & 0 & 0 \\
\hline Psychiatry & 0 & 1 & 1 \\
\hline Psychological pain therapy & 1 & 1 & 0 \\
\hline Psychosomatic medicine & 0 & 1 & \\
\hline Self-help organisations/patient representative & 1 & 2 & 0 \\
\hline Physiatry/physiotherapy & 1 & 0 & \\
\hline Others & 1 & 0 & \\
\hline $\begin{array}{l}\text { Competing interests of members of steering } \\
\text { committee }\end{array}$ & 9 & 10 & 9 \\
\hline Sources of financial support & $\begin{array}{c}\text { Louise and Alan } \\
\text { Edwards Foundation, } \\
\text { Valeant }\end{array}$ & $\begin{array}{l}\text { Scientific medical and } \\
\text { psychological societies; } \\
\text { self-help organisations }\end{array}$ & $\begin{array}{l}\text { Pfizer; scientific medical } \\
\text { and psychological } \\
\text { societies }\end{array}$ \\
\hline
\end{tabular}

reviewed by three external reviewers of different medical specialties and by the boards of the scientific societies involved. The Israeli recommendations were formulated based on strength of evidence identified (see Table 3).

3.5. Need for a Guideline. All three countries justified the need for development of guidelines on the basis of the high prevalence of FMS and the association of reduced healthrelated quality of life of patients and high healthcare costs as well as controversies surrounding diagnosis and management $[10,11,20]$. The prevalence rates of FMS — assessed by different methodologies-were comparable between the three countries: Canada 2-3\% [25], Germany 2.1\% [5], and Israel 2.6\% [3].

3.6. Recommendations for Definition and Classification. Recommendations concerning the definition, classification, clinical diagnosis, and general principles of care set out by all three guidelines were predominantly based on expert consensus, with very limited evidence available in the current literature.

All three guidelines defined FMS by the 1990 classification criteria of the American College of Rheumatology (ACR) classification criteria [1].
The Canadian guidelines stated that FMS is clinical construct of pain and other symptoms that cannot be explained by some other illness [10]. The German guidelines classified FMS as a functional somatic syndrome [13], defined by a typical cluster of symptoms and the exclusion of a somatic disease (e.g., endocrine or inflammatory) which sufficiently explains the symptoms [26]. The terms "FMS," "somatoform pain disorder," and "(masked) depression" are not interchangeable since not all patients with FMS meet the criteria of a somatoform pain disorder or a (masked) depression [13]. The Israeli guidelines [20] classified FMS to be a central hypersensitivity syndrome [27]. Both the Canadian and German guidelines identified FMS as a continuum disorder similar to other illnesses such as diabetes, rather than as a discrete disorder which could be present or absent at a particular time point. The prevalence of the syndrome depends on the cutoffs used for the definition of the disease/disorder, but is recognized as a condition that can wax and wane over time [10, 12].

3.7. Recommendations for Clinical Diagnosis. Details of the recommended diagnostic workup are outlined in Table 4.

Currently there is no specific diagnostic laboratory test or biomarker available for the diagnosis of FMS. All three guidelines were in agreement that the diagnosis remains 
TABLE 2: Comparison of the methodology of the Canadian, German, and Israeli guidelines.

\begin{tabular}{|c|c|c|c|}
\hline & Canada & Germany & Israel \\
\hline Needs assessment & $\begin{array}{l}\text { Structured consultation with } 139 \\
\text { healthcare professionals from } \\
\text { relevant disciplines }\end{array}$ & $\begin{array}{l}\text { Structured consultation within the } \\
\text { guideline group ( } 50 \text { persons building } 8 \\
\text { working groups) }\end{array}$ & $\begin{array}{l}\text { Structured consultation } \\
\text { within the guideline group }\end{array}$ \\
\hline Databases & $\begin{array}{l}\text { EMBASE, MEDLINE, } \\
\text { PSYCHINFO, PUBMED, and } \\
\text { Cochrane Library }\end{array}$ & $\begin{array}{l}\text { Medline, PsychINFO, SCOPUS, and } \\
\text { Cochrane Library }\end{array}$ & Medline, Cochrane Library \\
\hline Dates of search strategy & Until July 2010 & Until December 2010 & Until April 2012 \\
\hline Sources of evidence & $\begin{array}{l}\text { Systematic reviews, meta-analyses, } \\
\text { and clinical trials }\end{array}$ & $\begin{array}{l}\text { Systematic reviews with meta-analyses } \\
\text { of pain, fatigue, sleep problems, quality } \\
\text { of life, and drop out for any reasons in } \\
\text { randomised controlled trials } \\
\text { conducted by guideline group; harms } \\
\text { of therapies as reported in RCTs and in } \\
\text { the literature }\end{array}$ & $\begin{array}{c}\text { Systematic reviews, } \\
\text { meta-analyses, and clinical } \\
\text { trials }\end{array}$ \\
\hline $\begin{array}{l}\text { Sources of } \\
\text { recommendations }\end{array}$ & $\begin{array}{l}\text { Systematic reviews, meta-analyses, } \\
\text { RCTs, panel consensus, and } \\
\text { approval by } \geq 80 \% \text { of } 35 \text { members of } \\
\text { the National Fibromyalgia } \\
\text { Guidelines Advisory Panel } \\
\text { (NFGAP) }\end{array}$ & $\begin{array}{l}\text { Systematic reviews with meta-analyses } \\
\text { conducted by guideline group; } \\
\text { structured consensus conference* }\end{array}$ & $\begin{array}{c}\text { Systematic reviews, } \\
\text { meta-analyses, and RCTs; } \\
\text { panel consensus }\end{array}$ \\
\hline $\begin{array}{l}\text { Number of references in } \\
\text { the guideline document }\end{array}$ & 336 & 608 & 30 \\
\hline Classification of evidence & Oxford criteria & Oxford criteria & Oxford criteria \\
\hline $\begin{array}{l}\text { Classification of } \\
\text { recommendations }\end{array}$ & Oxford criteria & German national guidelines & $\begin{array}{l}\text { Recommendations based on } \\
\text { strength of evidence }\end{array}$ \\
\hline External review & $\begin{array}{c}\text { One international expert } \\
\text { Boards of both endorsing scientific } \\
\text { societies }\end{array}$ & Boards of scientific societies involved & $\begin{array}{l}\text { Chairman of Israel } \\
\text { Rheumatology Society }\end{array}$ \\
\hline Publication & In press & April 13, 2012 & In press \\
\hline Internet access & $\begin{array}{c}\text { http://www.canadianpainsociety.ca/ } \\
\text { pdf/Fibromyalgia_Guidelines_2012 } \\
\text {.pdf }\end{array}$ & $\begin{array}{l}\text { http://www.awmf.org/leitlinien/detail/ } \\
\text { 1l/041-004.html }\end{array}$ & $\begin{array}{c}\text { http://www.ima.org.il/Ima/ } \\
\text { FormStorage/Type7/clinical } \\
\text { _68_fibrom.pdf }\end{array}$ \\
\hline
\end{tabular}

${ }^{*}$ Strong consensus: $>95 \%$ of the participants consented; consensus: $75-95 \%$ of the participants consented; majority: $50-75 \%$ of the participants consented. A minority statement and an explanatory statement were possible.

RCT: randomized controlled trial.

clinical and the purpose of the physical examination and limited laboratory investigations is to rule out some other alternative diagnoses. The Canadian guidelines [10] recommended that the preliminary ACR 2010 diagnostic criteria may be used to validate a clinical diagnosis of FMS [28]. The German guidelines recommended [12] the use of the ACR 1990 classification criteria [1] or the modified ACR 2010 diagnostic criteria [4] or the AWMF criteria [29]. The Israeli guidelines did not make a specific recommendation regarding the use of 1990 or 2010 ACR criteria (which have yet to be formally adopted by the ACR).

The German guidelines recommended the use of the fibromyalgia survey questionnaire [30] to assess FMS-like symptoms and severity (see the supplementary Table in Supplementary Material online at http://dx.doi.org/10.1155/2013/ 528952).
Both the Canadian and the German guidelines stated that, for most patients, the diagnosis can be established by a primary care physician. A referral to a specialist (e.g., rheumatologist, neurologist, or endocrinologist) should be limited to situations when there is a reasonable clinical suspicion of some other condition that is presenting similarly to FMS or when the patient presents particular treatment challenges $[10,13]$.

All three guidelines emphasized that the diagnosis of FMS can coexist with a diagnosis of another somatic disease (e.g., inflammatory arthritis, osteoarthritis) or of a mental disorder (e.g., depression) [10,13, 20]. The German guidelines recommended active screening for mental disorder and referral to mental healthcare specialist in case of suspected mental disorder or maladaptive coping $[12,14]$. The Israeli guidelines recommended screening for symptoms of anxiety 
TABLE 3: Comparison of the categorisation of evidence (treatment) and recommendations of the Canadian, German, and Israeli guidelines.

\begin{tabular}{|c|c|c|c|}
\hline & Canada & Germany & Israel \\
\hline Evidence level I & $\begin{array}{l}\text { SR of randomised controlled } \\
\text { trials or n-of- } 1 \text { trial }\end{array}$ & $\begin{array}{l}\text { Ia-SR (with homogenity) of RCTs }{ }^{* *} \\
\text { Ib-individual RCT (with narrow } \\
\text { confidence Interval) } \\
\text { IC-all or none }\end{array}$ & $\begin{array}{l}\text { SR of randomised controlled trials } \\
\text { with large number of participants } \\
\text { (over 1000) }\end{array}$ \\
\hline Evidence level II & $\begin{array}{l}\quad \text { Randomized trial or } \\
\text { (exceptionally) observational } \\
\text { studies with dramatic effect }\end{array}$ & $\begin{array}{l}\text { IIa-SR (with homogeneity) of cohort } \\
\text { studies** } \\
\text { IIb-individual cohort study (including } \\
\text { low quality RCT; e.g., <80\% followup) } \\
\text { IIc-“Outcomes" research; Ecological } \\
\text { studies"* }\end{array}$ & $\begin{array}{l}\text { SR of observational studies, cohort } \\
\text { studies, or small randomized studies }\end{array}$ \\
\hline Evidence level III & $\begin{array}{l}\text { Nonrandomized controlled } \\
\text { cohort/follow-up study* }\end{array}$ & $\begin{array}{l}\text { IIIa-SR (with homogenity) of } \\
\text { case-control studies }{ }^{* *} \\
\text { IIIB-individual case-control study }{ }^{* *}\end{array}$ & Nonrandomized controlled studies \\
\hline Evidence level IV & $\begin{array}{l}\text { SR of case-control studies, } \\
\text { historically controlled studies }\end{array}$ & $\begin{array}{l}\text { Case-series (and poor quality cohort and } \\
\text { case-control studies) }{ }^{* *}\end{array}$ & $\begin{array}{l}\text { SR of case-control studies, open } \\
\text { studies, and case reports }\end{array}$ \\
\hline Evidence level V & Expert opinion & $\begin{array}{l}\text { Expert opinion without explicit critical } \\
\text { appraisal or based on physiology, bench } \\
\text { research, or "first principles"** }\end{array}$ & Expert opinion \\
\hline $\begin{array}{l}\text { Recommendation } \\
\text { strength A }\end{array}$ & Consistent level I studies & Directly based on evidence level I ${ }^{* * *}$ & $\begin{array}{c}\text { "Strong evidence": based on level I } \\
\text { evidence }\end{array}$ \\
\hline $\begin{array}{l}\text { Recommendation } \\
\text { strength B }\end{array}$ & $\begin{array}{c}\text { Consistent level } 2 \text { or } 3 \text { studies or } \\
\text { extrapolations from level } 1 \\
\text { studies }\end{array}$ & $\begin{array}{c}\text { Directly based on evidence level II or } \\
\text { extrapolated recommendation evidence } \\
\text { level I }{ }^{* * *}\end{array}$ & $\begin{array}{l}\text { "Medium evidence": based on level } \\
\text { II evidence }\end{array}$ \\
\hline $\begin{array}{l}\text { Recommendation } \\
\text { strength C }\end{array}$ & $\begin{array}{l}\text { Level } 4 \text { studies or extrapolations } \\
\text { from level } 2 \text { or } 3 \text { studies }\end{array}$ & $\begin{array}{l}\text { Directly based on evidence levels III, IV, } \\
\text { and } \mathrm{V}^{* * *}\end{array}$ & $\begin{array}{l}\text { "Weak evidence": } \\
\text { based on levels III-IV evidence }\end{array}$ \\
\hline $\begin{array}{l}\text { Recommendation } \\
\text { strength D }\end{array}$ & $\begin{array}{l}\text { Level } 5 \text { evidence or troublingly } \\
\text { inconsistent or inconclusive } \\
\text { studies of any level }\end{array}$ & & \\
\hline Panel consensus & $\begin{array}{l}\text { Opinion supported by entire } \\
\text { Canadian Fibromyalgia } \\
\text { Guidelines Committee }\end{array}$ & $\begin{array}{l}\text { Recommendation supported by majority } \\
\text { of guideline group }\end{array}$ & $\begin{array}{c}\text { Recommendation supported by } \\
\text { entire Israeli fibromyalgia group } \\
\text { panel }\end{array}$ \\
\hline
\end{tabular}

RCT: randomised controlled trial; SR: systematic review or meta-analysis.

${ }^{*}$ Level may be graded down on the basis of study quality, imprecision, and indirectness, because of inconsistency between studies or because the absolute effect size is very small; level may be graded up if there is a large or very large effect size.

${ }^{* *}$ Level may be graded down on the basis of study quantity ( $<4$ RCTs of $<200$ patients), study quality (low study quality according to van Tulder score), low external validity (exclusion of patients with inflammatory rheumatic diseases and/or anxiety or depressive disorders), and evidence of publication bias.

${ }^{* * *}$ An up- or downgrading of recommendations is possible depending on the consistency of the results of the studies, the clinical relevance of the outcomes and effect sizes of the studies, the benefit-harm ratio, ethical considerations, patients' preferences, and the applicability of the therapies.

${ }^{* * * *}$ The strength of consensus was classified as follows: strong consensus: consent of $>95 \%$, consensus: consent of $75-95 \%$, majority consent: consent of $50-75 \%$, and no consent: consent of $<50 \%$ of the participants. A minority vote with a substantial rationale was possible.

and depression as part of the initial evaluation [20]. The Canadian guidelines recommended that that the healthcare professional should be aware that psychological conditions may present with body pain [10].

3.8. Education after Initial Diagnosis of FMS. All three guidelines recommended that the diagnostic label "FM" or "FMS" should be communicated to patients after initial diagnosis and that patients should be provided with a clear explanation regarding the nature of the disorder, planned treatment strategy, and expected outcome $[10,11,20]$. This approach is intended to reduce anxiety, which inherently accompanies chronic pain [20]. There was also consensus that patients should be informed of the concept of a biopsychosocial model for FMS whereby biological factors (e.g., genetic predisposition) and psychosocial factors (e.g., stress) contribute to the predisposition, triggering, and perpetuating of FMS symptoms $[10,12,20]$. The Canadian guidelines discouraged excessive focus on a triggering event (such as a physical or psychological traumatic event) which could compromise patient care [10]. The German guidelines suggested that the following information could be useful in the education of patients.

(i) The symptoms are not caused by an organic disease (such as abnormality of muscles or joints) but are instead based on a functional disorder.

(ii) The legitimacy of the ailment should be acknowledged. 
TABLE 4: Comparison of the recommendations of the Canadian, German, and Israeli guidelines on the clinical diagnosis of FMS.

\begin{tabular}{ll}
\hline \multicolumn{1}{c}{ Canada } \\
\hline History of a typical cluster \\
of symptoms & $\begin{array}{l}\text { Diffuse body pain that has been } \\
\text { present for at least 3 months, } \\
\text { disturbance, cognitive changes, } \\
\text { mood disorder, and other } \\
\text { somatic symptoms to variable } \\
\text { degree }\end{array}$
\end{tabular}

Germany Israel

Presence of pain in muscles, joints, connective tissues, various areas of the upper and lower limbs, neck, shoulders, and upper and lower back

Chronic widespread pain and fatigue (physical and/or mental) and sleeping problems/unrefreshed sleep
Typical symptoms of sleep disturbances, difficulty falling asleep, frequent awakening during the night, disturbed sleep patterns, and unrefreshing sleep Chronic fatigue complaints throughout the day Difficulties with concentration and memory

Other disorders explaining the symptoms have been ruled out. FMS may develop in coexistence with additional disorders, be they somatic, inflammatory, psychiatric, or otherwise

Complete physical examination Complete blood count, renal function tests (creatinine and urea), serum calcium and phosphorous levels, liver function tests, creatine phosphokinase (CPK), erythrocyte sedimentation rate (ESR), C-reactive protein (CRP), thyroid stimulating hormone (TSH) and vitamin D

Full ble physical examination sedimentation rate (ESR),

Recommended methods C-reactive protein (CRP), creatine phosphokinase (CPK), and thyroid stimulating hormone (TSH)
Obtaining history of pharmacological agents used Complete physical examination Complete blood count, C-reactive protein (CRP), serum calcium, creatine phosphokinase $(\mathrm{CPK})$, and thyroid stimulating hormone (TSH)
Any additional laboratory or radiographic testing should

Further tests depend on the clinical evaluation in an individual patient that may suggest some other medical condition
At the discretion of the physician performing the evaluation, based on clinical hints pointing at a somatic disease. (low threshold for serological tests e.g., ANA and RF)

No requirement to document number of tender points; however, assessment of tenderness recommended as part of physical examination

Recommended Recommended

Screening for mental disorders

\begin{tabular}{ll} 
& FMS \\
\hline Diagnostic criteria & American College of \\
& $\begin{array}{l}\text { Rheumatology (ACR) 2010 } \\
\text { preliminary diagnostic criteria }\end{array}$
\end{tabular}

Facultative examination of soft tissues for generalized tenderness should be done
ACR 1990 classification criteria or ACR 2010 modified diagnostic criteria AWMF criteria
Clinical diagnosis, based on above evaluation (iii) The symptoms are persistent in nearly all patients.

(iv) Total relief of symptoms is seldom achieved.

(v) The symptoms do not lead to disablement and do not shorten life expectancy. (vi) Most patients learn to adapt to the symptoms over time.

(vii) The goals of treatment are improvement in quality of life, maintenance of function (functional ability in everyday situations), and reduction of symptoms. 
(viii) The ability of the patient to modulate symptoms via self-management strategies should be emphasized [11].

The German guidelines group developed a patient version of the guideline and handouts for patients and their significant others, which should be distributed to the patient after establishing the diagnosis [11].

\section{Discussion}

We have identified considerable consistency between three recently published FMS guidelines spanning three continents. This agreement observed for the classification and clinical steps to establishing a diagnosis of FMS should put to rest many of the contentious issues that have challenged the medical community regarding this condition [8]. It should now be fully accepted that FMS is neither a distinct rheumatic disease nor a mental disorder, but a syndrome defined by a typical cluster of symptoms, with the exclusion of some other illness which sufficiently explains the symptoms. While FMS was originally defined by the ACR 1990 classification criteria [1], the cluster of symptoms which defines FMS goes beyond chronic widespread pain and tenderness. Physical and/or mental fatigue and sleep disturbance resulting in unrefreshed sleep are other key symptoms. Most patients report the presence of additional somatic and psychological symptoms. The existence of polysymptomatic distress, or symptoms beyond body pain, constitutes a "minor" diagnostic criterion of the preliminary ACR 2010 diagnostic criteria [28] and subsequent modification for survey and clinical use [4].

The diagnosis of FMS can be readily established in most cases by primary care physicians following a history of a typical cluster of symptoms and a defined diagnostic workup, including a complete medical history and physical examination and some simple and selected laboratory tests to exclude a somatic disease that sufficiently explains the symptoms. The modifier "sufficiently" in this definition is of critical importance and must be acknowledged: FMS often coexists with other disorders and the presence of such comorbidities must not be interpreted as ruling out a diagnosis of FMS. Thus, FMS is not a diagnosis of exclusion but rather a positive clinical diagnosis important to recognise, either independent of or in addition to other medical problems. In most patients diagnosed with FMS, more than one diagnosis is necessary to capture the whole spectrum of symptoms. Most importantly, other functional somatic syndromes (e.g., irritable bowel syndrome), mental disorders (e.g., depression or posttraumatic stress disorder), and somatic diseases (e.g., inactive or slightly active inflammatory rheumatic disease) can be diagnosed $[12,20]$.

A tender point examination is not obligatory for the diagnosis of FMS. This physical finding, subject to variable interpretation and which reflects an overall reduction in pain threshold, has at times been inappropriately used to establish a diagnosis of FMS. A referral to a specialist should be reserved for those selected patients in whom there is a suspicion of some other somatic disease and/or of mental disorder or when there are specific treatment challenges. Excessive healthcare utilization with referral to multiple specialists and repeated radiographic and laboratory investigations should be discouraged. The use of the (modified) ACR 2010 diagnostic criteria $[4,28]$, which do not require tender point examination, is recommended for clinical diagnosis, but should not preclude a thorough physical examination. While some patients with FMS will still be referred to rheumatologists, mostly to exclude some other rheumatic condition, FMS should no longer be identified as an exclusive rheumatic syndrome.

It is reassuring that the concordance rates of the different diagnostic criteria of FMS are high (80-90\%) [29, 30]. This reinforces the true existence and validity of a condition that has caused so much consternation over the years. The concept of FMS, however, remains a work in progress with many current unanswered clinical and pathophysiologic questions. These recent guidelines as well as the revision of criteria for the diagnosis of FMS are clearly steps towards a better understanding of this condition. The ACR 2010 criteria will also likely lead to higher rates of FMS diagnosis in men because healthy [31] as well as men diagnosed with FMS [32] have less tender points than women.

\section{Conclusions}

FMS, often disputed and challenged, has emerged as a clinical syndrome with a clear cluster of symptoms and comorbidities. Despite the ongoing paucity of biomarkers available for diagnosing and monitoring of this condition, a systematic evidence-based approach can lead to effective, patientcentered management with avoidance of unnecessary and harmful interventions.

The cluster of symptoms that we today recognize as FMS has been described in the literature for over 200 years, with the specific diagnostic label of FMS introduced at the end of the 20th century [33]. The recent evidence-based interdisciplinary guidelines developed in Canada, Germany, and Israel should give healthcare professionals confidence to positively diagnose this condition, avoid excessive testing and medical consultation, and facilitate patient care by emphasis on appropriate patient education and active patient participation in healthcare plan.

\section{Conflict of Interests}

Mary-Ann Fitzcharles has received consulting fees, speaking fees, and/or honoraria from Biovale, Janssen, Lilly, Pfizer, Purdue, and Valeant (less than $\$ 10,000$ ) within the last 3 years. Yoram Shir has received consulting fees, speaking fees, and/or honoraria from Janssen, Pfizer, Purdue, Astra Zeneca, and Paladin labs. (less than $\$ 10,000$ ) within the last 3 years. Jacob N. Ablin has received consulting fees, speaking fees of less than $\$ 10,000$ from Pfizer, Lilly, and MSD within the last 3 years. Howard Amital has no conflict of interests to declare. Peter Henningsen has received speaking fees of less than $\$ 10,000$ from Lilly and Novartis within the last 3 years. Winfried Häuser has received consulting fees and speaking fees from Abbott, Daiichi Sankyo, and Pfizer (less than $\$ 10,000$ ) within the last 3 years. 


\section{References}

[1] F. Wolfe, H. A. Smythe, M. B. Yunus et al., "The American College of Rheumatology 1990. Criteria for the classification of Fibromyalgia. Report of the Multicenter Criteria Committee," Arthritis and Rheumatism, vol. 33, no. 2, pp. 160-172, 1990.

[2] J. C. Branco, B. Bannwarth, I. Failde et al., "Prevalence of Fibromyalgia: a survey in five European countries," Seminars in Arthritis and Rheumatism, vol. 39, no. 6, pp. 448-453, 2010.

[3] J. N. Ablin, A. Oren, S. Cohen et al., "Prevalence of Fibromyalgia in the Israeli population: a population-based study to estimate the prevalence of Fibromyalgia in the Israeli population using the London Fibromyalgia Epidemiology Study Screening Questionnaire (LFESSQ)," Clinical and Experimental Rheumatology, vol. 30, no. 6, supplement 74, pp. 39-43, 2012.

[4] F. Wolfe, D. J. Clauw, M.-A. Fitzcharles et al., "Fibromyalgia criteria and severity scales for clinical and epidemiological studies: a modification of the ACR preliminary diagnostic criteria for Fibromyalgia," Journal of Rheumatology, vol. 38, no. 6, pp. 1113$1122,2011$.

[5] F. Wolfe, E. Brähler, A. Hinz et al., "Fibromyalgia prevalence, somatic symptom reporting, and the dimensionality of polysymptomatic distress: results from a survey of the general population," Arthritis Care \& Research, vol. 65, no. 5, pp. 777-785, 2013.

[6] W. Häuser, C. Zimmer, E. Felde, and V. Köllner, "What are the key symptoms of Fibromyalgia? Results of a survey of the German Fibromyalgia Association," Schmerz, vol. 22, no. 2, pp. 176-183, 2008 (German).

[7] A. Chandran, C. Schaefer, K. Ryan et al., "The comparative economic burden of mild, moderate, and severe Fibromyalgia: results from a retrospective chart review and cross-sectional survey of working-age U.S. adults," Journal of Managed Care Pharmacy, vol. 18, no. 6, pp. 415-426, 2008.

[8] F. Wolfe, "Fibromyalgia wars," Journal of Rheumatology, vol. 36, no. 4, pp. 671-678, 2009.

[9] M. Harth and W. R. Nielson, "The Fibromyalgia tender points: use them or lose them? A brief review of the controversy," Journal of Rheumatology, vol. 34, no. 5, pp. 914-922, 2007.

[10] M. A. Fitzcharles, P. A. Ste-Marie, D. L. Goldenberg et al., "2012 Canadian Guidelines for the diagnosis and management of Fibromyalgia syndrome: executive summary," Pain Research \& Management, vol. 18, no. 3, pp. 119-126, 2013.

[11] W. Häuser, K. Bernardy, H. Wang et al., "Methodological fundamentals of the development of the guideline," Schmerz, vol. 26, no. 3, pp. 232-246, 2012 (German).

[12] W. Eich, W. Häuser, B. Arnold et al., "Fibromyalgia syndrome. General principles and coordination of clinical care and patient education," Schmerz, vol. 26, no. 3, pp. 268-275, 2012 (German).

[13] W. Eich, W. Häuser, B. Arnold et al., "Fibromyalgia syndrome. Definition, classification, clinical diagnosis and prognosis," Schmerz, vol. 26, no. 3, pp. 247-267, 2012 (German).

[14] V. Köllner, W. Häuser, K. Klimczyk et al., "Psychotherapy for patients with Fibromyalgia syndrome. Systematic review, metaanalysis and guideline," Schmerz, vol. 26, no. 3, pp. 291-296, 2012 (German).

[15] J. Langhorst, W. Hauser, K. Bernardy et al., "Complementary and alternative therapies for Fibromyalgia syndrome. Systematic review, meta-analysis and guideline," Schmerz, vol. 26, no. 3, pp. 311-317, 2012 (German).
[16] C. Sommer, W. Häuser, R. Alten et al., "Drug therapy of Fibromyalgia syndrome. Systematic review, meta-analysis and guideline," Schmerz, vol. 26, no. 3, pp. 297-310, 2012 (German).

[17] B. Arnold, W. Häuser, M. Arnold et al., "Multicomponent therapy of Fibromyalgia syndrome. Systematic review, meta-analysis and guideline," Schmerz, vol. 26, no. 3, pp. 287-290, 2012 (German).

[18] A. Winkelmann, W. Häuser, E. Friedel et al., "Physiotherapy and physical therapies for Fibromyalgia syndrome. Systematic review, meta-analysis and guideline," Schmerz, vol. 26, no. 3, pp. 276-286, 2012 (German).

[19] C. Sommer, W. Häuser, M. Burgmer et al., "Etiology and pathophysiology of Fibromyalgia syndrome," Schmerz, vol. 26, no. 3, pp. 247-258, 2012 (German).

[20] J. N. Ablin, H. Amital, M. Ahrenfeld et al., "Guidelines for the diagnosis and treatment of the Fibromyalgia syndrome," Harefuah, 2013 (Hebrew), http://www.ima.org.il/Ima/FormStorage/ Type7/clinical_68_fibrom.pdf.

[21] University of Texas, School of Nursing, Family Nurse Practitioner Program, Management of Fibromyalgia Syndrome in Adults, University of Texas, School of Nursing, 2009.

[22] C. A. de Miquel, J. Campayo, M. T. Flarez et al., "Interdisciplinary consensus document for the treatment of Fibromyalgia," Actas Españolas de Psiquiatría, vol. 38, no. 2, pp. 108-120, 2010.

[23] Oxford Centre for Evidence-Based Medicine, "Levels of Evidence and Grades of Recommendation," http://www.cebm.net/ index.aspx?o=1025\#levels.

[24] G. Ollenschläger and I. Kopp, "The German program for disease management guidelines. Results and perspectives," Medizinische Klinik, vol. 15, no. 5, pp. 383-387, 2007 (German).

[25] J. D. McNally, D. A. Matheson, and V. S. Bakowsky, "The epidemiology of self-reported Fibromyalgia in Canada," Chronic Diseases in Canada, vol. 27, no. 1, pp. 9-16, 2006.

[26] R. Mayou and A. Farmer, "ABC of psychological medicine: functional somatic symptoms and syndromes," British Medical Journal, vol. 325, no. 7358, pp. 265-268, 2002.

[27] M. B. Yunus, "Fibromyalgia and overlapping disorders: the unifying concept of central sensitivity syndromes," Seminars in Arthritis and Rheumatism, vol. 36, no. 6, pp. 339-356, 2007.

[28] F. Wolfe, D. J. Clauw, M.-A. Fitzcharles et al., "The American College of Rheumatology preliminary diagnostic criteria for Fibromyalgia and measurement of symptom severity," Arthritis Care \& Research, vol. 62, no. 5, pp. 600-610, 2010.

[29] W. Häuser, S. Hayo, W. Biewer et al., "Diagnosis of Fibromyalgia syndrome-a comparison of association of the medical scientific societies in germany, survey, and american college of rheumatology Criteria," Clinical Journal of Pain, vol. 26, no. 6, pp. 505-511, 2010.

[30] W. Häuser, E. Jung, B. Erbslöh-Möller et al., "Validation of the Fibromyalgia survey questionnaire within a cross-sectional survey," PLoS One, vol. 7, no. 5, Article ID e37504, 2012.

[31] F. Wolfe, K. Ross, J. Anderson, I. J. Russell, and L. Hebert, “The prevalence and characteristics of Fibromyalgia in the general population," Arthritis and Rheumatism, vol. 38, no. 1, pp. 19-28, 1995.

[32] W. Häuser, H. Kühn-Becker, H. von Wilmoswky, M. Settan, E. Brähler, and F. Petzke, "Demographic and clinical features of patients with Fibromyalgia syndrome of different settings: a 
gender comparison," Gender Medicine, vol. 8, no. 2, pp. 116-125, 2011.

[33] S. Perrot, "If Fibromyalgia did not exist, we should have invented it. A short history of a controversial syndrome," Reumatismo, vol. 64 , no. 4 , pp. 86-93, 2012. 


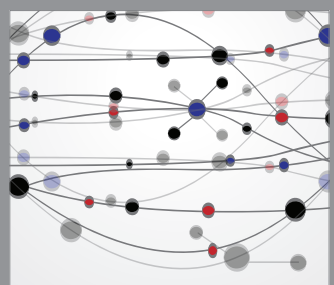

The Scientific World Journal
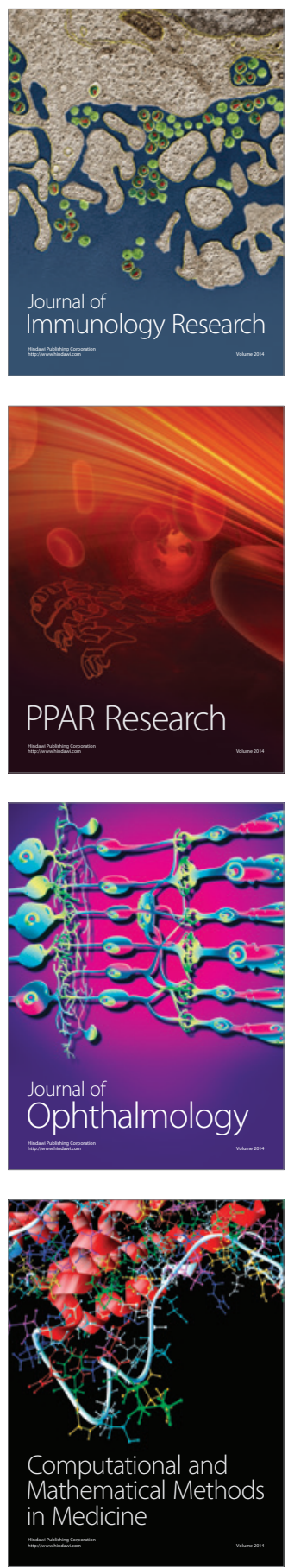

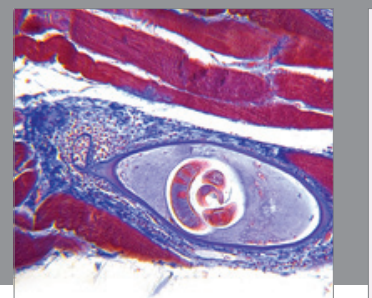

Gastroenterology

Research and Practice
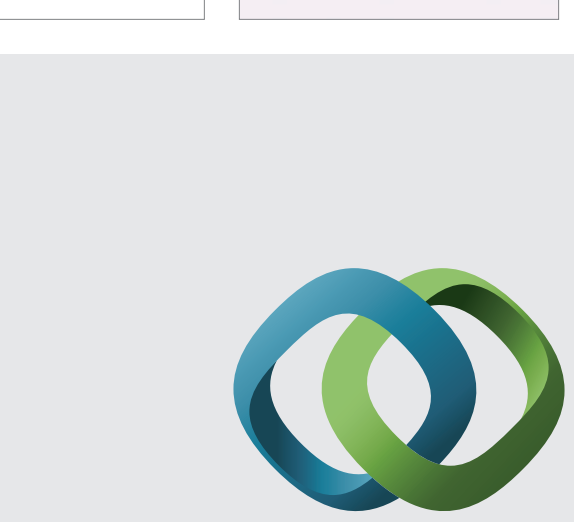

\section{Hindawi}

Submit your manuscripts at

http://www.hindawi.com
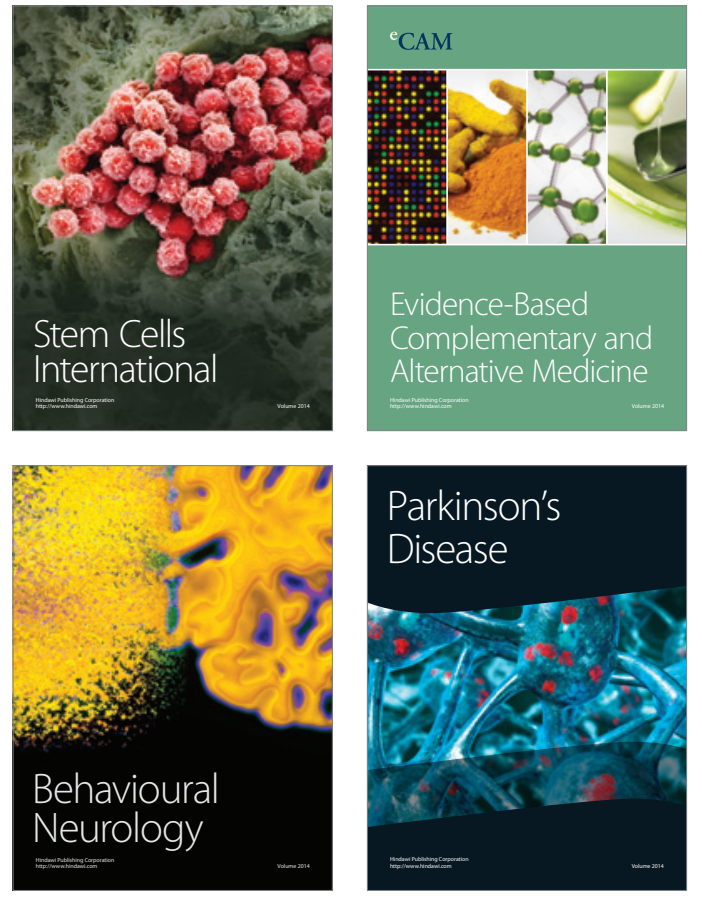
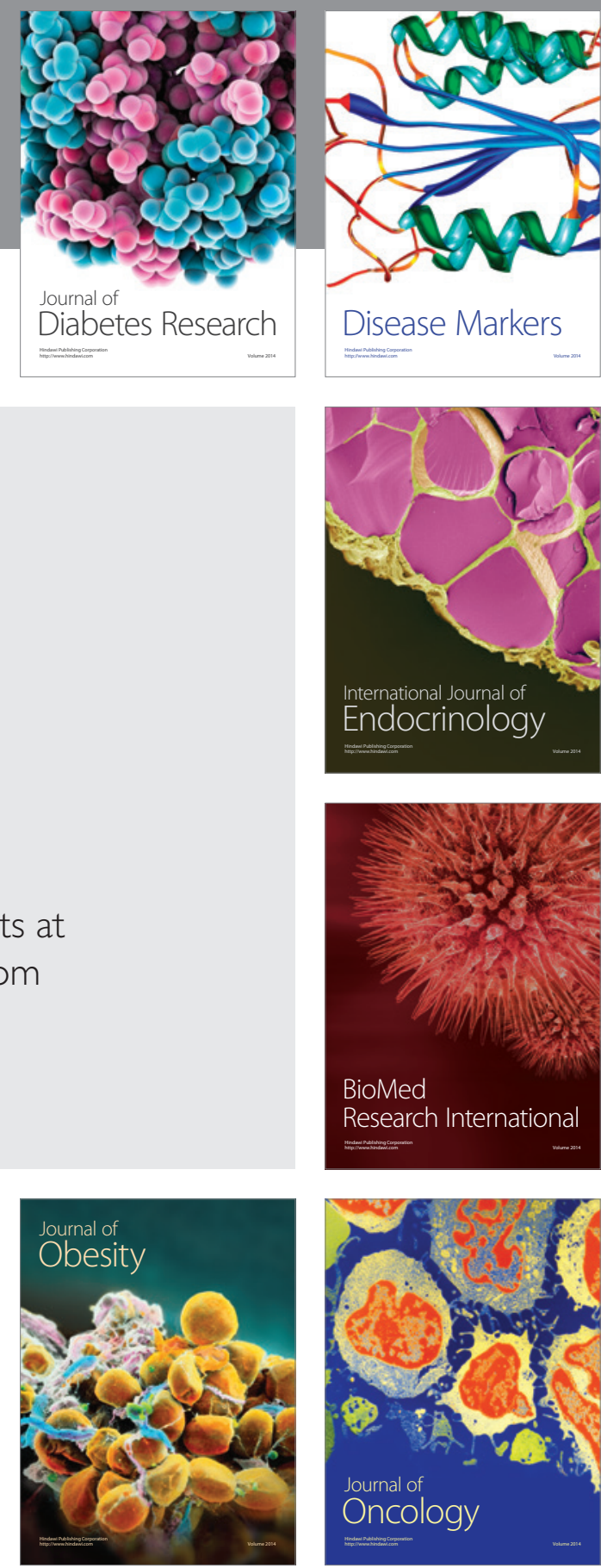

Disease Markers
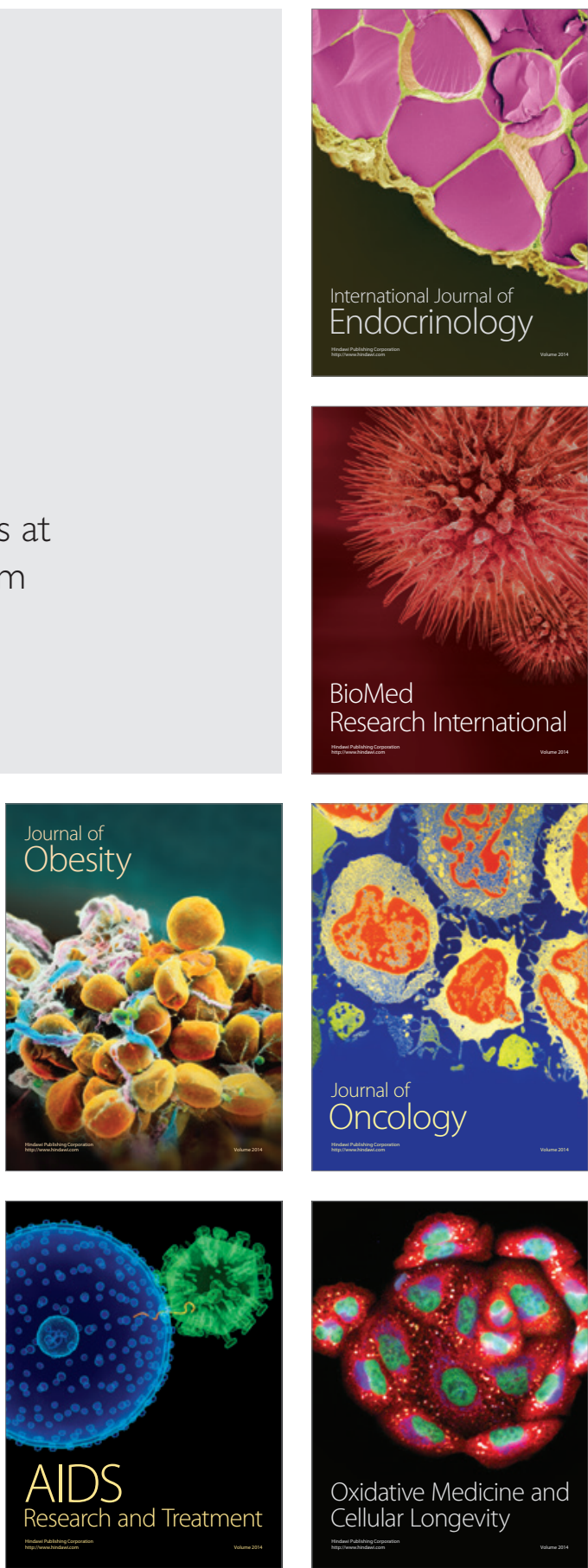